\title{
FATORES DE COOPERAÇÃO NO INSTITUTO FEDERAL DE SANTA CATARINA
}

DOI: http://dx.doi.org/10.18616/pidi15

Alberto Felipe Friderichs Barros - IFSC E-mail: alberto.barros@ifsc.edu.br Simone Meister Sommer Biléssimo - UFSC E-mail: simone.bilessimo@ufsc.br Solange Maria da Silva UFSC E-mail: sunsilva2015@gmail.com Patrícia de Sá Freire - UFSC

E-mail: patriciasafreire@gmail.com 


\section{INTRODUÇÃO}

Para que um país obtenha êxito no atual cenário econômico, é preciso que possua diferenciais competitivos sustentáveis. Uma das alternativas para potencializar essa capacidade competitiva está na busca de cooperação Universidade-Empresa (U-E), a fim de aproveitar os conhecimentos e a ação investigativa da Universidade para a geração de inovações empresariais necessárias (ALTHEMAN, 2010).

Dagnino (2003) destaca a importância das empresas buscarem alianças estratégicas a partir de pesquisas cooperativas. Nesse sentido, a cooperação entre U-E se tornou objeto de estudo crescente nas últimas décadas.

No entanto, a inovação estabelece grandes desafios, considerados por alguns autores, tais como Drucker (1989), Etzkowitz (2003) e Segatto-Mendes (1996), um processo de difícil articulação, de grandes investimentos, de alto risco e elevado grau de incertezas, fazendo com que a maioria das empresas não aposte nessa estratégia.

Sabe-se, porém, que as empresas inovadoras obtêm vantagens competitivas sobre seus concorrentes, como: aumento da receita e lucros, redução de preços, geração de empregos, geração de novos conhecimentos, dentre outras.

A Organização de Cooperação de Desenvolvimento Econômico (OCDE, 2005) destaca a grande importância do setor produtivo no contexto geral da pesquisa, desenvolvimento e inovação. Entretanto, as empresas necessitam de forte apoio do governo para desenvolver essas atividades, devido ao alto risco e ao elevado grau de incerteza inerentes a essas atividades.

Assim, surge o modelo da Tríplice Hélice, preconizado por Etzkowitz e Leydesdorff (1995), que propõem uma relação trilateral entre a política promovida pelo governo, a ciência realizada na universidade e a tecnologia desenvolvida na empresa. Ao governo impõe-se a necessidade de criar um ambiente favorável a essas cooperações, ampliando a participação do setor produtivo com o ambiente de pesquisa localizado nas universidades e nos institutos de pesquisa.

A cooperação universidade-empresa tem se mostrado uma alternativa positiva para o desenvolvimento tecnológico, de modo a promover vantagens para os dois lados envolvidos, auxiliando na obtenção dos objetivos, mesmo que eles se apresentem de formas distintas. 
Apesar de todas as vantagens advindas da cooperação universidade-empresa, existe uma série de barreiras organizacionais ocasionadas basicamente pelas diferenças nas características e nos objetivos almejados por ambas as partes. Para Vasconcellos, Waack e Vasconcellos (1997), a universidade tem como meta principal investir na geração de conhecimentos e tecnologia para o desenvolvimento da sociedade em geral. Já a empresa concentra suas atenções na geração de receitas, sem as quais não sobreviveria nem desempenharia sua função social de criar empregos e atender à sociedade, transformando a tecnologia em um instrumento para garantir a sua participação no mercado.

Em outro sentido, a intensificação dessas relações tem dado origem a diversos conflitos: a compatibilização de tarefas do professor, que continua suas atividades na universidade, e a propriedade dos resultados da pesquisa, que são alguns exemplos citados por Marcovitch (1999).

Diante do exposto, essa pesquisa tem como objetivo analisar a relação de cooperação entre empresas privadas e o Instituto Federal de Santa Catarina, destacando os principais fatores motivacionais, as barreiras e os benefícios que originam essas cooperações.

A opção por analisar a cooperação no âmbito do Instituto Federal de Santa Catarina - IFSC se deu pelo fato de a instituição possuir em sua missão o papel de agente promotor do desenvolvimento científico e tecnológico, difundindo conhecimento e inovação. Outro fator que motivou a escolha do tema foi que poucos trabalhos foram encontrados na literatura, na abordagem da cooperação, no âmbito dos institutos federais.

Para Clark (2003), a inovação pode representar para as empresas uma resposta da ciência à sua busca cada vez maior por diferenciação, sendo chave para a sua sustentabilidade em um mercado altamente competitivo. As universidades precisam, igualmente, desenvolver capacidades que garantam sua sustentabilidade, adaptando-se a essa sociedade em transformação.

\section{CONHECIMENTO E INOVAÇÃO}

Ao longo dos anos, o conhecimento vem evoluindo. No entanto, sua importância para os meios de produção é que tem tido um impacto mais relevante. 
O conhecimento, em todas as suas formas, desempenha hoje um papel crucial em processos econômicos. As nações que desenvolvem e gerenciam efetivamente seus ativos de conhecimento têm melhor desempenho que outras. Os indivíduos com maior conhecimento obtêm empregos mais bem remunerados. Este papel estratégico do conhecimento é ressaltado pelos crescentes investimentos em pesquisa e educação. A estrutura de políticas deve, portanto, dar ênfase à capacidade de inovação e criação de conhecimento nas economias dos países. É por isto que, em longo prazo, ela gera empregos e renda adicionais, uma das principais tarefas dos governos é criar condições que induzam as empresas a realizarem os investimentos e as atividades inovadoras necessárias para promover a mudança técnica (OCDE, 2005, p. 17).

Coser, Reis e Carvalho (2008) enfatizam que o grande desafio para as empresas está em criar condições para armazenar e desenvolver novos conhecimentos. Acumular conhecimento significa aprender, não no sentido estrito de uma formação, mas num contexto mais amplo, em que se pode falar em formação organizacional. Nesse contexto, a universidade tem sido considerada pela sociedade um celeiro, se não único, indispensável de novas ideias. Impõe-se, portanto, a necessidade de estreitar sua relação com o setor produtivo, gerando e difundindo conhecimento e inovação.

A inovação e o conhecimento desempenham papéis fundamentais no cenário econômico (ETZKOWITZ; 2003; CHAIMOVICH, 1999), sendo um dos principais fatores que definem a competitividade e o desenvolvimento de um país.

Para Nonaka e Takeuchi (1997), inovação é recriar o mundo de acordo com uma perspectiva específica ou ideal. Assim, afirmam que o processo de criação de conhecimento é o combustível para a inovação, pois envolve tanto ideias como ideais.

Dávila, Guillermo e Silva (2008) propõem uma relação entre pesquisa científica e inovação. Conforme os autores, a inovação é sustentada por uma base de conhecimento e de pesquisa científica, que atuará como um catalisador na ampliação de fatores para o sucesso do processo inovador.

Segundo o Manual de Oslo (OCDE, 2005, p. 41), a inovação “[...] é vista como um processo dinâmico em que o conhecimento é acumulado por meio do aprendizado e da cooperação". Nesse sentido, pode-se dizer que o conhecimento é o que dá o suporte necessário para a inovação. 
Greenhalgh e Rogers (2010) destacaram que a inovação é definida como algo novo para a empresa e para o mercado e que pode ser local ou global.

\begin{abstract}
Uma inovação é a implementação de um produto, bem ou serviço, novo ou significativamente melhorado, ou um processo, ou um novo método de marketing, ou ainda um novo método organizacional nas práticas de negócios, na organização do local de trabalho ou nas relações externas (OCDE, 2005, p. 55).
\end{abstract}

Hu (2003) apresenta a inovação como um processo de produção de conhecimento, exigindo criatividade e envolvendo a incerteza com relação aos resultados. Já Tirole (1995) enfatiza a ideia do posicionamento competitivo. As empresas inovam para defender sua atual posição de mercado, assim como para buscar novas vantagens competitivas. Elas podem ter um comportamento reativo e inovar para evitar perder mercado ou podem ter um comportamento proativo e ganhar posições diante de seus concorrentes.

Para Schumpeter (1997), a principal razão pela qual as empresas inovam é porque elas estão em busca de lucros. Assim, desenvolver uma nova tecnologia traz muita vantagem competitiva para a empresa e, caso a inovação ocorra em um processo que eleve sua produtividade, ela também obterá vantagem sobre seus concorrentes, produzindo mais com menos recursos.

Corroborando a ideia de desenvolvimento econômico, Torres (2014) destaca que o domínio tecnológico adquiriu um valor econômico expressivo como fator de sobrevivência das empresas, assim sobrevive a empresa que incorpora de forma contínua a inovação de seus produtos e processos.

Para Grupp (1998), a inovação é uma consequência do desenvolvimento da ciência e da tecnologia, cujos resultados são alcançados, principalmente, por meio de uma intensa atividade de pesquisa e desenvolvimento - P\&D.

Pode-se afirmar que há um consenso de que o processo de inovação envolve investimentos, tempo, incertezas e riscos. A inovação está associada à incerteza sobre os resultados, já que não se sabe de antemão qual será o resultado dessas atividades inovadoras. Conforme Machado e Souza (2016), a inovação é um investimento de risco, pois a maioria das ideias que são testadas não se tornam realmente inovações, gerando, algumas vezes, prejuízos que a empresa precisa absorver. Tal condição já é um fator desestimulante para as 
pequenas e, até mesmo, para as médias empresas, que podem ver todo seu capital comprometido pelo fracasso de uma tentativa de inovação.

Rogers (2003) explica que o processo de inovação é algo complexo e variável, não sendo, no geral, representado de maneira exata como acontece. 0 autor prossegue dizendo que, de maneira tradicional, sua representação ocorre de maneira linear, partindo da universidade para a empresa.

Todavia, o processo de inovação pode ser encarado como um fenômeno sistêmico e irreversível, ao longo do que o ambiente configura a empresa inovadora, tal como a empresa configura seu próprio ambiente, mas não enquanto um projeto isolado de inovação.

Para Autio (1997), a inovação não será notada, necessariamente, enquanto um processo linear, mas sim como um resultado de uma cooperação complexa entre diversos atores e instituições. Tais atores e instituições e suas respectivas interconexões formarão um sistema de agentes intrinsecamente interdependentes. Portanto, um sistema de inovação é caracterizado pelos agentes de inovação: universidades, institutos federais, centros de pesquisa, empresas, governos, fundações de amparo à pesquisa, entre outros.

Etzkowitz (2003, p. 299) conceitua a cooperação entre atores como um elemento consolidado no próprio termo inovação que, "[...] mais do que o desenvolvimento de novos produtos nas empresas, é ou tem sido considerado mais recentemente também como a criação de novos arranjos entre as esferas institucionais que propiciam as condições para a inovação".

Rapini (2014) destaca que a cooperação universidade-empresa (U-E) vem sendo estimulada como objeto de política em diversos países. Para isso, diversas iniciativas de fomento dos governos, tais como concessão de fundos, recursos não reembolsáveis para projetos em parceria, incentivos fiscais, programas específicos para fomento, entre outros, vêm sendo desenvolvidas.

\section{COOPERAÇÃO UNIVERSIDADE-EMPRESA (U-E)}

A cooperação universidade-empresa pode ser definida como um conjunto de interações, que objetivam a criação e difusão do conhecimento e que envolvem relações diretas e indiretas entre empresas e universidades/institutos de pesquisa (COSTA; PORTO; PLONSKI, 2010). 
Para Plonski (1992, p. 18), "Inclui-se neste conceito desde interações tênues e pouco comprometedoras, como o oferecimento de estágios, até vinculações mais intensas como a repartição dos créditos resultantes da comercialização dos seus resultados".

Segundo Fischmann e Cunha (2003), a cooperação universidade-empresa torna-se cada vez mais importante no contexto econômico contemporâneo. Isso porque as universidades passam a buscar uma nova definição do papel que ocupam na sociedade, enquanto as empresas buscam novas alternativas para competir e assegurar sua sobrevivência nesse mercado.

Para Alves e Pimenta-Bueno (2014), a cooperação universidade-empresa assume estruturas organizacionais muito variadas, dependentes da maturidade da relação, dos objetivos da cooperação, etc., mas toda essa variedade resulta em uma mesma finalidade: o desafio relevante intelectual para as universidades e a produção complementar de conhecimento para a empresa ao menor custo.

Marcovitch (1999) entende que, da mesma forma que a universidade necessita encontrar a maneira adequada de se relacionar com o setor de produção, este deve entender como solicitar a colaboração da universidade. É preciso que ocorra uma intervenção de agentes que melhor articulem essa relação, valorizando a interdisciplinaridade, papel que cabe também ao governo.

Mota (1999) contribui, explicando que o governo se torna responsável pelo fomento de políticas públicas de incentivo ao processo de inovação, bem como pela maior parte do financiamento que é preciso para a realização de pesquisas. Sendo assim, deve partir do governo a formulação de leis e políticas de incentivo ao processo de cooperação (TECCHIO et al., 2010), já que a composição da tríplice hélice tem no governo um papel determinante para estimular e implementar as ações e leis, assim como criar mecanismos que são considerados essenciais para o processo de cooperação.

Fonseca (2001) comenta que o papel central do governo, no que tange à inovação tecnológica, é o provimento de incentivos adequados para o desenvolvimento e disseminação de ideias do setor privado. Além disso, deve promover um ambiente político, econômico e institucional que seja estimulante às empresas para que invistam em ciência, tecnologia, pesquisa e desenvolvimento.

Segatto-Mendes (1996) entende que é possível, dessa maneira, dividir a atuação do governo em duas vertentes: a primeira delas é a educação, visando 
à geração de capital humano; a segunda, a infraestrutura, que envolve a criação de um centro de pesquisas, de uma rede de comunicação, entre outras. Isso é compreedido, todavia, como uma barreira de relacionamento entre os agentes, cuja visão é de que a responsabilidade é do Estado, por ser o único financiador das atividades de pesquisa universitárias.

Sendo assim, todo o contexto aponta para uma relação complexa entre governo, universidade e empresa, com base em múltiplos interesses que, muitas vezes, são concorrentes entre si. Também é apontado que o governo possui um papel determinante para a mediação e incentivo da parceria universidade-empresa, podendo ser considerado o seu principal incentivador, cada vez mais fundamental na procura por respostas às problemáticas que são enfrentadas pela sociedade.

\section{MOTIVAÇÕES E BARREIRAS}

De acordo com Segatto-Mendes e Sbragia (2002), é necessário que haja compreensão das motivações e expectativas que levam as universidade e as empresas a pesquisarem em conjunto, tanto no processo como um todo quanto em relação aos benefícios que podem ser alcançados por meio dele.

Carvalho (2011) afirma que as motivações impulsionam as relações para o bom processo de cooperação, uma vez que buscam satisfazer as necessidades diferentes da universidade e da empresa, mas que, ao mesmo tempo, se complementam na geração de conhecimentos necessários para o desenvolvimento.

$\mathrm{Na}$ abordagem do modelo conceitual de Segatto-Mendes e Sbragia (2002), os autores apontam algumas motivações, as quais são apresentadas no Quadro 1. 
Quadro 1 - Motivações da Cooperação

\begin{tabular}{|l|l|}
\hline \multicolumn{1}{|c|}{ Empresa } & \multicolumn{1}{c|}{ Universidade } \\
\hline • Acesso aos recursos humanos & $\bullet$ Recursos financeiros adicionais; \\
especializados; & $\bullet$ Realização da função social; \\
• Redução de custos e riscos; & • Divulgação da imagem da universidade; \\
- Acesso a novos conhecimentos; & • Aumento dos conhecimentos sobre os problemas \\
• Identificação de alunos para recrutamento. & existentes. \\
\hline
\end{tabular}

Fonte: Segatto-Mendes e Sbragia (2002).

Webster (1994) complementa, justificando as razões para a ampliação das relações entre a Universidade e a Empresa: custo crescente da pesquisa ao desenvolvimento de produtos e serviços e elevado risco de investimentos e incertezas, ao passo que as motivações do lado da universidade seriam a facilidade na obtenção de recursos públicos para a pesquisa universitária e a geração e obtenção de novos conhecimentos.

Alves e Pimenta-Bueno (2014) destacam que a cooperação também possibilita o acesso a recursos públicos de fomento à inovação. Segundo os autores, esse é um dos maiores motivadores na formação da parceria

Por outro lado, Souza (2015), Segatto-Mendes (1996) e Marcovitch (1999) destacam que pesquisas empíricas revelaram que, apesar das vantagens resultantes desse relacionamento, existe uma complexidade de fatores envolvidos nessa relação, podendo gerar dificuldades as quais, por vezes, impedem a finalização do processo da forma como desejada pelos atores envolvidos. Dentre os fatores, encontram-se: as questões relacionadas ao tempo de resposta diante das necessidades empresariais, os entraves para a conquista da propriedade intelectual, a baixa inserção de acadêmicos em atividades industriais, o enfoque da universidade na ciência básica (de longo ciclo) e não no desenvolvimento ou comercialização de produtos e serviços, além de uma imagem de elevada burocracia nas universidades.

Nesse contexto, Gomes (2014) advoga que para a universidade facilitar o processo de cooperação, é necessário diminuir a burocracia existente, a fim de que os excessos de encargos burocráticos não atrasem o desenvolvimento de pesquisas conjuntas.

Porto (2000) complementa essa abordagem, apresentando as variáveis que identificam potenciais barreiras na relação universidade-empresa, como disposto no Quadro 2. 
Quadro 2 - Barreiras de Cooperação

\begin{tabular}{|l|l|l|}
\hline \multicolumn{1}{|c|}{ Estruturais } & \multicolumn{1}{|c|}{ Motivacionais } & \multicolumn{1}{c|}{ Procedimentais } \\
\hline - Falta de administração & • Existência, por parte das & • Complexidade dos contratos a \\
dos projetos de forma & empresas, de desconfiança; & serem firmados; \\
profissional nas & - Existência de dúvida sobre & • Falta de experiência em trabalho \\
universidades; & o valor da cooperação; & interdisciplinar; \\
- Altos custos envolvidos; & • Os procedimentos & - Distância física e psicológica entre \\
- Indefinições na & necessários à realização e & os envolvidos no projeto; \\
elaboração de clara política \\
institucional de & manutenção de um acordo \\
relacionamento com o & cooperativo são vistos como \\
ambiente externo. & excesso de trabalho. & contratação de transferência de \\
\end{tabular}

Fonte: Porto (2000).

Para Albiero Berni (2015), questões como o distanciamento, a burocracia, as diferenças culturais, o desinteresse do corpo acadêmico e da administração, aliadas ao baixo acesso à universidade, são ressaltadas pelos empresários como entraves para o estabelecimento de parcerias com as instituições de ensino, pesquisa e extensão.

Costa e Cunha (2001) apontam que existem, ainda, limitações de diversos graus por parte dos agentes envolvidos na modificação de seus procedimentos e formas de atuação. A conscientização da necessidade de flexibilização e adaptação precisa ser incentivada, uma vez que a cristalização de posicionamentos pode encaminhar à perda de oportunidades, sobretudo relacionadas à globalização.

\section{O MODELO DA TRÍPLICE HÉLICE}

O Modelo da Tríplice Hélice, termo cunhado por Etzkowitz e Leydesdorff, no início da década de 2000 , propõe uma relação dinâmica entre governo, ciência realizada na universidade e tecnologia desenvolvida na empresa. Os autores sugerem que apenas por meio da cooperação entre governo, universidade e empresa é possível criar um sistema de inovação sustentável e durável, em uma economia baseada no conhecimento (ETZKOWITZ, 2002).

Etzkowitz e Leydesdorff (2000), Etzkowitz e Mello (2004), Abdalla et al. (2009) e Toscano e Ribeiro (2009) apontam que o modelo de cooperação entre governo, universidade e empresa enfrentou evoluções ao longo do tempo, causadas por ideias incrementais. Explicam que o modelo envolve três atores 
e, por isso, apresentam três pás diferentes da mesma hélice: a indústria, que funciona como o espaço de produção; o governo, que se apresenta como pá da hélice responsável pela fonte de relações contratuais, as quais asseguram as interações estáveis; e, finalmente, a universidade, que funciona como fonte de novos conhecimentos e tecnologias.

Etzkowitz e Leydesdorff (2000) afirmam, ainda, que as interações entre agentes também se encontram em evolução constante, o que passa a demandar novas formas para a representação geométrica desse processo. Nesse sentido, para suprimir a falta de interação entre as esferas institucionais, surge a terceira fase, que representa o modelo da Tríplice Hélice.

Referido modelo foi concebido na metade da década de 1990 e apresentado nos textos pioneiros de Etzkowitz e Leydesdorff, publicados em 1995 e 1996. Na terceira etapa, existe uma aproximação intensa e fomenta-se a cooperação entre as instituições, podendo existir alguma atuação de um agente na área do outro. Nesse ponto, prevê-se uma infraestrutura de conhecimento com a sobreposição de esferas institucionais, sendo que cada uma delas pode exercer o papel da outra e formar organizações híbridas na emergência de suas interfaces (ETZKOWITZ; LEYDESDORFF, 2000).

Etzkowitz (2002) comenta que a Tríplice Hélice será, então, um modelo a fim de oferecer uma tratativa para lidar com a inovação, buscando na captura de múltiplas e recíprocas relações, em distintos pontos do processo de geração de conhecimento, a melhor forma de fazer essa gestão.

Cohen et al. (2002) observaram que o processo para a geração de inovação não se dá de maneira linear, de forma que os novos conhecimentos não seguem o caminho da ciência para o setor produtivo. Essa visão era comum na década de 1970. Na contemporaneidade, o fluxo reverso é possível e os desenvolvimentos ou problemas tecnológicos que são observados em empresas originam novas pesquisas científicas.

Terra e Plonski (2006) destacam que a cooperação entre academia, indústria e governo requererá uma nova aprendizagem, além da comunicação e de uma rotina de serviços em instituições a fim de produzir, difundir e regular processos de geração e aplicação do conhecimento. Assim, a Tríplice Hélice poderá ser entendida como uma forma metafórica de representar um mecanismo que possibilita aos atores criar uma dinâmica de cooperação entre eles e entre todos os demais agentes sociais, promovendo o progresso por meio da ação de empreendedorismo e inovação. 
Etzkowitz (2003) aponta que a transição para uma sociedade com base no conhecimento se torna uma premissa básica para o modelo da Tríplice Hélice, cuja configuração faz com que a universidade tenha um papel de coadjuvante, passando a ocupar uma função de maior predominância. Nesse sentido, o modelo destaca-se para convencer a universidade a cooperar com o sistema produtivo em que governo, universidade e indústria se unem em prol do desenvolvimento tecnológico nacional (DAGNINO, 2003).

\section{O INSTITUTO FEDERAL DE SANTA CATARINA}

O Instituto Federal de Santa Catarina é uma instituição pública federal vinculada ao Ministério da Educação - MEC e supervisionada pela Secretaria de Educação Profissional e Tecnológica - SETEC. Tem sede e foro na cidade de Florianópolis, capital do estado de Santa Catarina, possuindo autonomia administrativa, patrimonial, financeira, didático-pedagógica e disciplinar (IFSC, 2012). Ao longo do tempo, a instituição sofreu diversas transformações, até que por meio da Lei $n^{\circ} 11.892 / 2008$ passou a integrar a rede federal de educação profissional e tecnológica.

Com o processo de expansão da rede federal, ocorrido em 2010, o IFSC ampliou e possui, atualmente, uma reitoria e vinte e um campi distribuídos na capital, Florianópolis, e nos seguintes municípios: Araranguá, Criciúma, Tubarão, Garopaba, Palhoça, São José, Itajaí, Joinville, Florianópolis (Continente), Gaspar, Lages, Caçador, Canoinhas, Chapecó, São Carlos, Xanxerê, São Miguel do Oeste, Jaraguá do Sul, Geraldo Werninghaus e São Lourenço do Oeste.

Possui em seu quadro o total de 2.353 servidores, sendo 1.081 técnicos administrativos e 1.272 professores. Oferta 643 cursos, sendo 143 técnicos, 36 graduações, 22 especializações, um mestrado e 441 cursos de formação inicial e continuada, atendendo a uma demanda de aproximadamente $32 \mathrm{mil}$ alunos (IFSC, 2012).

O IFSC realiza pesquisa científica e tecnológica, levando em conta o avanço tecnológico e as necessidades da sociedade. Além disso, faz a articulação com instituições de fomento e com o setor produtivo, com vistas ao desenvolvimento regional e ao fortalecimento do campo científico e tecnológico do país (IFSC, 2012). 


\section{METODOLOGIA}

São diversas formas para se classificar as pesquisas, porém, a fim de alcançar os objetivos evidenciados pelo presente estudo, utilizou-se a elaborada por Miguel (2010), que considera que uma pesquisa científica pode ser categorizada a partir de quatro aspectos: quanto à natureza da pesquisa; à forma de abordagem do problema; aos objetivos; e aos procedimentos técnicos.

Levando-se em consideração a natureza desta pesquisa, ela se enquadra como aplicada (PRODANOV; FREITAS, 2013). Ainda, em relação à classificação proposta, à pesquisa enquadra-se como sendo uma abordagem qualitativa (COLLIS; HUSSEY, 2005). Assim, visa entender, descrever e explicar os fenômenos sociais de modos diferentes, por meio da análise de experiências individuais e grupais, exame de interações e comunicações que estejam em desenvolvimento, assim como de investigação de documentos (textos, imagens, filmes ou músicas) ou de traços semelhantes de experiências e integrações (FLICK, 2009).

Quanto a seus objetivos, a pesquisa é classificada como exploratória (GIL, 2010). Quanto aos procedimentos técnicos de pesquisa, foi utilizada a pesquisa bibliográfica e o estudo de caso (GIL, 2010). Para compreender pelo olhar do Instituto Federal de Santa Catarina os fatores de cooperação com empresas do setor produtivo, optou-se pela realização do estudo de caso (YIN, 2001).

O trabalho teve base na pesquisa bibliográfica, que possibilitou o estudo de conceitos e o embasamento teórico necessário à compreensão das relações de cooperação universidade-empresa e inovação. O referencial teórico se deu a partir de livros, dissertações, teses e artigos científicos de revistas nacionais e internacionais. Foram utilizadas as seguintes bases de dados: Periódicos Capes, Scopus e Biblioteca Digital Brasileira de Teses e Dissertações.

Capes: A revisão utilizando o Portal de Periódicos Capes foi realizada por meio de uma busca avançada, cujas palavras-chave foram cooperação Universidade-Empresa and Inovação. Essa investigação encontrou 60 resultados. Para classificação foi utilizado o critério de aderência ao estudo em questão, assim foi realizada uma análise criteriosa dos títulos e dos resumos dos estudos.

Scopus: A revisão da literatura realizada na base de dados Scopus utilizou a palavra-chave University-Industry e obteve 2048 resultados.

Banco de Teses e Dissertações: Pesquisas de mestrado e doutorado relevantes ao estudo em questão foram encontradas na Biblioteca Digital Bra- 
sileira de Teses e Dissertações - BDTD. Foi realizada uma busca avançada utilizando-se as palavras-chave cooperação Universidade-Empresa and Inovação no título e assunto, sendo encontradas 23 publicações.

Nem todas as publicações consultadas foram utilizadas na pesquisa. Os arquivos resultantes dessas buscas foram filtrados, classificados e separados por grau de relevância, o que resultou em 35 artigos que lhe serviram de base.

Para a coleta de dados, foi eleito o procedimento de pesquisa com survey (SANTOS, 1999). Os dados primários foram coletados por meio de questionário semiestruturado com perguntas fechadas, abertas e de múltiplas escolhas, com espaços para comentários adicionais a critério do respondente. $\mathrm{O}$ questionário foi elaborado com o auxílio da ferramenta Google Formulários. As questões foram formuladas com base no trabalho desenvolvido por Segatto-Mendes (1996), levando-se em consideração a análise conceitual a partir do referencial teórico e os objetivos da pesquisa.

Foram elaboradas 20 questões, que trataram das variáveis cooperação IFSC-empresa, motivações, barreiras e inovação, adotando-se o formato da escala tipo Likert (SAMPIERI; COLLADO; LUCIO, 2006). As questões foram categorizadas em função de sua concordância e importância, respectivamente.

Para aplicar o questionário, primeiramente foi necessário o cadastro da pesquisa na Plataforma Brasil, para obtenção de parecer do comitê de ética em pesquisas com seres humanos. Após parecer favorável, a pesquisa foi apresentada à Pró-Reitoria de Pesquisa do Instituto Federal de Santa Catarina para autorização de aplicação no IFSC. A partir disso, foi encaminhando no dia 7 de novembro de 2016 o termo de consentimento livre e esclarecido - TCLE, juntamente com o link do questionário para preenchimento on-line. O questionário foi enviado para o e-mail dos respondentes, sendo eles os coordenadores de pesquisa e extensão dos campi do Instituto Federal de Santa Catarina, totalizando 22 pessoas que receberam o convite para participar da pesquisa.

Posteriormente ao envio dos questionários, foram feitos contatos telefônicos para confirmar seus recebimentos e ressaltar a finalidade e a importância da participação do campus na pesquisa. O questionário ficou disponível no período de 07 a 17 de novembro de 2016. Os dados foram processados no próprio site de pesquisa, com o auxílio de planilhas eletrônicas que viabilizaram a análise descritiva dos resultados. Os dados secundários foram obtidos pelo NIT do IFSC e tratam dos depósitos de registros de patentes no INPI. 
Para a análise e a interpretação dos dados, seguiu-se a metodologia adotada por Segatto-Mendes (1996), utilizando-se a média ponderada. Conforme Segatto-Mendes e Sbragia (2002), estabeleceu-se o critério de que os valores acima de três significam a aceitação da variável e, portanto, valores abaixo significam a não aceitação.

\section{DISCUSSÃO DOS RESULTADOS}

A primeira parte do questionário relacionou a questões de identificação, tipos, quantidades e duração das parcerias. A primeira pergunta foi se o campus do respondente possuía cooperações com empresas privadas. A análise dos dados mostrou que a maioria dos campi possui algum tipo de parceria com empresas privadas, totalizando 15 campi que possuem parcerias, contra apenas um que não possui. A justificativa apresentada por este respondente foi por se tratar de um campus novo e devido à falta de estrutura e de pessoal.

Identificou-se, ainda, que metade dos campi possui entre um e quatro cooperações. Cinco campi responderam que possuem entre cinco e 10 cooperações e apenas dois campi responderam que possuem mais de 10 cooperações. Para complementar esses dados, solicitou-se aos respondentes que informassem quais seriam os tipos de cooperações. A preponderância das cooperações se dá em projetos de pesquisa, seguidos por estágios e empregos, visitas técnicas e palestras. Percebe-se que há uma predominância de cooperações do tipo informal, justamente em virtude da redução da complexidade e da burocracia.

A questão seguinte abordou a duração ou vigência das cooperações firmadas. Constatou-se que $92 \%$ das cooperações possuem vigência de, no máximo, até três anos. Em seguida, questionou-se como se dá a busca pelas cooperações. As respostas apontaram que a maior iniciativa parte do IFSC (93\%), contra $7 \%$ de iniciativas por parte da empresa.

$\mathrm{Na}$ literatura, os fatores de cooperação universidade-empresa encontrados podem ser classificados como Motivacionais e Limitadores. Em relação às principais motivações que levam à busca pela cooperação do setor produtivo foram obtidos os seguintes resultados: todas as opções de aspectos motivadores para a busca da cooperação foram marcadas de maneira equilibrada. A principal motivação apontada, que se mostra indispensável na visão dos respondentes, 
foi o incentivo à pesquisa e à inovação. O incentivo se dá, principalmente, por meio de editais de pesquisas, os quais preveem o financiamento de bolsas para os alunos e recursos adicionais para o projeto.

Outro fator motivador e indispensável é que a cooperação ajuda a elevar o prestígio da imagem institucional em razão da comunidade e da região onde o campus está inserido. Isso ajuda a divulgar a imagem institucional e acaba por influenciar a procura por cursos. A inserção de alunos no mercado de trabalho é um fator muito importante que motiva a cooperação, segundo os pesquisados, pois é importante para a instituição que os alunos tenham uma boa colocação no mercado de trabalho.

O acesso a novos conhecimentos e a realização de função social também foram considerados muito importantes, visto que fazem parte de sua missão e de seu papel como instituição de ensino.

Destacam-se, também, os recursos financeiros adicionais, considerados muito importantes para o financiamento dos projetos de pesquisa e cooperação. Em suma, é o governo que, por meio de editais de pesquisas, prevê esses recursos financeiros e acaba fomentando as pesquisas acadêmicas. Por fim, as publicações auxiliam na divulgação e no reconhecimento dos pesquisadores.

É significativo ressaltar que foram consideradas pouco importantes, na visão dos pesquisados, a resolução de problemas técnicos e a redução de custos e riscos dos projetos de pesquisa. Por outro lado, existem diversas barreiras ou fatores limitadores. Nesse aspecto, identificou-se que os itens também foram marcados de maneira equilibrada. A principal barreira apontada foi a burocracia institucional, visto que, segundo os pesquisados, existem documentações excessivas, prazos e processos institucionais que impedem e dificultam o estabelecimento de parcerias. Um dos respondentes apontou que os processos são burocráticos e demorados e que a empresa privada tem urgência. Outra justificativa foi que há pouco ou nenhum interesse do campus devido à burocracia, fator inibidor para a inovação. Outra barreira fortemente apontada é a regulamentação vigente, que não favorece. Conforme justificativa, também há falta de conhecimento avançado sobre a legislação, descontinuidade de projetos, recursos insuficientes e a carga horária dos professores.

Em relação às discordâncias identificadas, muitos apontaram que a distância é um aspecto limitador, tendo em vista que o IFSC é representado estrategicamente em todas as regiões do estado de Santa Catarina. 
No tocante aos benefícios obtidos pelo Instituto Federal com a cooperação encontram-se empregos e estágios para alunos, realização de função social, publicações científicas, divulgação e prestígio da imagem e acesso a novos conhecimentos. Em seguida, perguntou-se que nota (entre zero e dez) os respondentes dariam para a atuação do IFSC no relacionamento com as empresas. Dentre os resultados, é possível notar que as médias são preponderantes, assim o IFSC obteve a nota cinco (5), o que caracteriza uma atuação inferior às expectativas dos respondentes.

Em alguns campi, foi possível perceber que houve pouco interesse pelo tema. As justificativas apresentadas pelos participantes foram as seguintes: participação quase insignificante, com parcerias na região; campus novo com quadro de servidores ainda incompleto; pouco ou nenhum interesse do campus devido à burocracia; poucas ações para o fortalecimento das parcerias; déficit na comunicação com o setor produtivo; falta de conhecimento avançado sobre a legislação; falta de pessoal qualificado para atender às demandas; processos burocráticos e demorados e a urgência das empresas privadas; priorização do ensino em detrimento da pesquisa.

De acordo com os dados coletados na pesquisa de campo, por meio de questionário, foi possível identificar a ocorrência de inovações em alguns campi. A pergunta foi se o campus já desenvolveu algum tipo de inovação. Foram obtidos os seguintes resultados: já houve desenvolvimento de inovações em oito campi; a quantidade apontada pelos participantes, ao todo, foi 14 , dividida em produtos (9), processos (3), marketing (1) e organizacional (1).

A fim de complementar a pesquisa, foram solicitados dados referentes ao depósito de patentes referente ao período de 2009 a 2016 no NIT do IFSC. Tem-se, pela percepção dos respondentes, que o depósito de patentes representa o fator de inovação da Instituição. Conforme os dados do Núcleo de Inovação Tecnológica do IFSC, destaca-se que, no ano de 2016, o campus Florianópolis foi responsável pelo pedido de seis (6) registros de patentes no INPI.

Outros dados complementares foram apresentados, os quais revelam que o IFSC vem cumprindo o seu papel por meio da pesquisa científica, da extensão e da inovação. É possível afirmar que os projetos de pesquisas realizados em 2016 ultrapassaram a quantidade de 118, isso porque alguns campi não responderam à questão. É importante destacar também a criação de spin-offs. Assim, verifica-se que há iniciativas de inovação em alguns campi, por meio de 
cooperação. Todavia, é necessário ampliar esses números e reduzir o hiato que separa a empresa da universidade.

\section{CONSIDERAÇÕES FINAIS}

O principal objetivo desta pesquisa foi investigar os principais fatores de cooperação universidade-empresa no Instituto Federal de Santa Catarina, sob à luz da teoria da Tríplice Hélice.

Esse modelo descrito por Etzkowitz e Leydesdorff, no início da década de 2000, propõe uma relação dinâmica entre o governo, a ciência realizada na universidade e a tecnologia desenvolvida na empresa. Os autores sugerem que apenas por meio da cooperação entre governo, universidade e empresa é possível criar um sistema de inovação sustentável e durável em uma economia baseada no conhecimento.

Dentre os modelos apresentados, o modelo aplicado neste novo paradigma da sociedade do conhecimento é o modelo de Tríplice Hélice III, cuja dinâmica se baseia na eficiência que os indivíduos e grupos possuem para se organizarem livremente sem que haja a necessidade de intermediação do governo. Nessa abordagem, o IFSC está inserido entre as esferas universidade e governo, podendo, por meio de editais, estimular a pesquisa cooperativa.

Autores como Etzkowitz e Leydesdorff (2000), Bekkers e Freitas (2008) sugerem que a cooperação entre universidade e empresa não fique restrita às atividades de pesquisa localizadas no ambiente universitário. No contexto brasileiro, a base governamental vem realizando esforços para o fortalecimento das atividades inovativas no país, incentivando, entre outras coisas, o financiamento de projetos que visam alavancar a interação entre o setor público e o privado, assim como o desenvolvimento de mecanismos legais para impulsionar a cooperação.

Diante disso, o estudo se propôs a compreender os fatores de cooperação, com vistas a responder à seguinte questão de pesquisa: Quais fatores de cooperação universidade-empresa destacam-se no âmbito do Instituto Federal de Santa Catarina?

Por conseguinte, tendo em vista a importância da inovação e do conhecimento para o desenvolvimento econômico e social na atualidade, esta 
pesquisa teve como objetivo principal identificar os principais fatores de cooperação universidade-empresa no Instituto Federal de Santa Catarina.

A partir dos resultados da pesquisa realizada, foram obtidas as seguintes conclusões: as maneiras de cooperação entre universidade e empresa encontradas na literatura podem se configurar de diversas maneiras, desde cursos de extensão, pesquisas, consultoria, projetos cooperativos, palestras, dentre outras. Resultados que são benéficos tanto para o desempenho profissional dos estudantes envolvidos quanto para as empresas parceiras. Em relação aos tipos de cooperação, observou-se uma predominância de acordos de cooperação informais, tais como: palestras, visitas técnicas, cursos e estágios, dentre outras. Esse vínculo é mais fácil de ser estabelecido devido à eliminação da burocracia.

Com relação às motivações, um fator que foi considerado indispensável, na visão dos pesquisadores, é o incentivo à pesquisa e à inovação, aparecendo, em seguida, como fatores muito importantes a imagem institucional e a inserção dos alunos no mercado de trabalho.

Com relação às principais barreiras apontadas, apareceram fortemente ligadas ao processo de gestão a burocracia institucional, a carga horária dos professores e os problemas de comunicação.

Apesar de a universidade e de a empresa possuírem características, missões e objetivos diferentes, é necessário que essas dimensões consigam enxergar pontos em comum para que possam ampliar essas relações de cooperação, de forma a ampliar também os benefícios.

Nos campi avaliados, dentre os benefícios das relações de cooperação universidade-empresa, notou-se a inserção de alunos no mercado de trabalho, fator apontado como motivador pelos respondentes. Todavia, notou-se, ainda, que esses campi, no geral, mantêm relacionamentos curtos de cooperação com as empresas.

Sendo assim, as empresas que formam essa relação de cooperação, bem como as empresas spin-offs, que resultam de projetos acadêmicos, encontram na inovação tecnológico-científica seu principal diferencial no mercado, além da chave para o êxito e sua sobrevivência.

Contudo, pode-se concluir que, embora alguns campi possuem atividades de inovação ligadas a empresas, isso ainda ocorre de forma tímida, o que nos leva à conclusão de que, de forma geral, o IFSC pouco contribui para a inovação a partir da cooperação, aspecto que poderia ser fortalecido por meio de ações institucionais. 
Dessa forma, como desdobramento deste trabalho, será apresentado à Pró-Reitoria de Pesquisa, Pós-Graduação e Inovação e ao NIT do IFSC os resultados desta pesquisa, de modo a possibilitar uma análise e uma revisão do processo de cooperação, a fim de melhorar as relações interinstitucionais, bem como avaliar formas de reduzir as barreiras que emperram o processo, possibilitando a elaboração de práticas de manutenção e aperfeiçoamento das políticas internas relacionadas à cooperação e à inovação.

Assim, o desafio se renova, ou seja, o IFSC tem, neste novo século, a missão de levar para a sociedade os conhecimentos adquiridos nas pesquisas e transformar a ciência em desenvolvimento econômico, gerando maior riqueza e bem-estar social para o país. Nessa questão, ainda há um longo caminho a percorrer.

\section{REFERÊNCIAS BIBLIOGRÁFICAS}

ABDALLA, M. et al. Hélice tríplice no Brasil: um ensaio teórico acerca dos benefícios da entrada da universidade nas parcerias estatais. Revista Cadernos de Administração, v. 1, p. 52-69, 2009.

ALBIERO BERNI, J. C. et al. Interação universidade-empresa para a inovação e a transferência de tecnologia. Revista Gestão Universitária na América Latina GUAL, Florianópolis, v. 8, n. 2, p. 258-277, maio 2015.

ALTHEMAN, E. Cooperação universidade-empresa: panorama, empecilhos e proposta para uma universidade ativa e empreendedora. Revista Viderere Futura, v. 1, p. 1-9, 2010.

ALVES, A. da S.; PIMENTA-BUENO, J. A. Uma análise exploratória do financiamento público à interação universidade-empresa no Brasil. Produção, v. 24, n. 4, p. 898-910, 2014.

AUTIO, E. New, technology-based firms in innovation networks symplectic and generative impacts. Research Policy, n. 26, p. 263-281, 1997.

AUTIO, E. Universities and industry: To what degree do sectors also matter? Research Policy, v. 37, p. 1837-1853, 2008.

BEKKERS, R.; FREITAS, I. M. B. Analysing knowledge transfer channels between universities and industry: To what degree do sectors also matter? Research Policy, v. 37, p. 1837-1853, 2008. 
BRASIL. Lei no 11.892, de 29 de dezembro de 2008. Institui a Rede Federal de Educação Profissional, Científica e Tecnológica, cria os Institutos Federais de Educação, Ciência e Tecnologia, e dá outras providências. Diário Oficial [da] República Federativa do Brasil. Brasília, DF, 20 dez. 2008. Disponível em: <http:// www.planalto.gov.br/ccivil_03/_ato2007-2010/2008/lei/l11892.htm>. Acesso em: 07 jan. 2016.

CARVALHO, N. Gestão da Cooperação: Fatores Facilitadores do Sistema Integrado de Acompanhamento de Resultados de Projetos. 2011. 132 p. Dissertação (Mestrado em Administração) - Universidade Federal de Lavras, Lavras, 2011.

CHAIMOVICH, H. Por uma relação mutuamente proveitosa entre universidade de pesquisa e empresas. Revista de Administração, São Paulo, v. 34, n. 4, p. 1822, out./dez. 1999.

CLARK, B. R. Sustaining change in universities: continuities in case studies and concepts. Tertiary Education and Management, v. 9, n. 2, p. 99-116, 2003.

COHEN, W. M. et al. The influence of public research on industrial R\&D. Management Science, v. 48, n. 1, p. 1-23, jan. 2002.

COLLIS, J.; HUSSEY, R. Pesquisa em Administração: Um guia prático para alunos de graduação e pós-graduação. 2. ed. Porto Alegre: Bookman, 2005.

COSER, M. A.; REIS, D. R.; CARVALHO, H. G. Práticas de Gestão do Conhecimento em Empresas de Tecnologia da Informação: nível de "conhecimento" e "experiência" dos engenheiros de software. In: ENCONTRO NACIONAL DE ENGENHARIA DE PRODUÇÃO, 28., Rio de Janeiro, 2008. Anais... Rio de Janeiro: Enegep/Abepro, 2008. $11 \mathrm{p}$.

COSTA, P. R. da; PORTO, G. S.; PLONSKI, G. A. Gestão da cooperação empresauniversidade nas multinacionais brasileiras. Revista de Administração $e$ Inovação, v. 7, n. 3, p. 150-173, 2010.

COSTA, V. M. G.; CUNHA, J. C. A universidade e a capacitação tecnológica das empresas. Revista de Administração Contemporânea, v. 5, n. 1, p. 61-81, 2001.

DAGNINO, R. A relação Universidade-Empresa no Brasil e o Argumento da Hélice Tripla. Revista Brasileira de Inovação, Campinas, v. 2, n. 2, jul./dez. 2003.

DÁVILA, C.; GUILLERMO A.; SILVA, E. L. Inovação no contexto da sociedade do conhecimento. Revista Textos de la Cibersociedad, Barcelona, n. 8, 2008.

DRUCKER, P. F. As fronteiras da Administração. São Paulo: Pioneira, 1989. 
ETZKOWITZ, H. Innovation in Innovation: the triple helix of university-industrygovernment relations. Social Science Information, v. 42, n. 3, p. 293-337, sept. 2003. Disponível em: <http://ssi.sagepub.com/content/42/3/293>. Acesso em: 07 jan. 2016.

ETZKOWITZ, H. The triple helix of university-industry-government implications for policy and evaluation. Stockholm: Institutet for studier av utbildning och forskning, 2002. [Working paper].

ETZKOWITZ, H.; LEYDESDORFF, L. The dynamics of innovation: from national systems and "mode 2" to triple helix of university-industry-government relations. Research Policy, v. 29, n. 2, p. 109-123, 2000.

ETZKOWITZ, H.; LEYDESDORFF, L. Universities and the global knowledge economy: a triple helix of university-industry-government relations. EASST Review, v. 14, n. 1, p. 14-19, 1995.

ETZKOWITZ, H.; MELLO, J. M. C. The Rise of a Triple Helix Culture: Innovation in Brazilian Economic and Social Development. International Journal of Technology Management and Sustainable Development, v. 2, n. 3, p. 159-171, 2004.

FISCHMANN, A. A.; CUNHA, N. C. V. da. Alternativas de ações estratégicas para promover a interação Universidade-Empresa através dos escritórios de transferência de tecnologia. In: SEMINÁRIO LATINOIBEROAMERICANO DE GeStíon TECNOLÓGICA, 10., Cidade do México, 2003. Anais... Cidade do México: Altec, 2003, v. 1.

FLICK, U. Desenho da pesquisa qualitativa. Porto Alegre: Artmed, 2009.

FONSECA, R. Inovação tecnológica e o papel do governo. Revista Parcerias Estratégicas, n. 13, dez. 2001.

GIL, A. C. Como elaborar projetos de pesquisa. 5. ed. São Paulo: Atlas, 2010.

GOMES, M. S. A inovação como conexão para o desenvolvimento de parcerias entre universidade-empresa. Revista Gestão e Tecnologia, Florianópolis, v. 4, n. 2, 2014.

GREENHALGH, C.; ROGERS, M. Innovation, intelectual property, and economic growth. New Jersey: Princeton University Press, 2010.

GRUPP, H. Foundations of the Economics of Innovation Theory, Measurement and Practice: New Horizons in the Economics of Innovation series. Massachusetts: Edward Elgar Publishing, 1998. 
HU, A. R\&D Organization, monitoring intensity and innovation performance in Chinese industry. Econ. Innov. New Techn., v. 12, 2003.

INSTITUTO FEDERAL DE SANTA CATARINA - IFSC. Missão, Visão e Valores. Publicado em 2012. Disponível em: <https://caco.ifsc.edu.br/menuinstitucional/missao>. Acesso em: 30 jan. 2016.

MACHADO, B. V.; SOUZA, A. R. O público e o privado na gestão da inovação no Brasil. Cadernos UniFOA, Volta Redonda, n. 30, p. 69-81, abr. 2016.

MARCOVITCH, J. A cooperação da universidade moderna com o setor empresarial. Revista de Administração, São Paulo v. 34, n. 4, p. 13-17, 1999.

MIGUEL, P. A. C. Metodologia de pesquisa em engenharia de produção. Rio de Janeiro: Elsevier, 2010.

MOTA, T. L. N. G. Interação Universidade-Empresa na sociedade do conhecimento: reflexões e realidades. Revista Ciência da Informação, Brasília, v. 28, n. 1, 1999. NONAKA, I.; TAKEUCHI, H. Criação de conhecimento na empresa: como as empresas japonesas geram a dinâmica da inovação. Rio de Janeiro: Campus, 1997.

ORGANIZAÇÃO PARA A COOPERAÇÃO E O DESENVOLVIMENTO ECONÔMICO OCDE. Manual de Oslo: Proposta de Diretrizes para Coleta e Interpretação de Dados sobre Inovação Tecnológica. 3. ed. Rio de Janeiro: Finep, 2005. Disponível em: <http://www.uesc.br/nucleos/nit/manualoslo.pdf>. Acesso em: 22 jan. 2016.

PLONSKI, G. A. Cooperación empresa-universidade em Iberoámerica. São Paulo: Programa CYTED, 1992.

PORTO, G. S. A decisão empresarial de desenvolvimento tecnológico por meio da cooperação Universidade-Empresa. São Paulo: FEA-USP, 2000.

PRODANOV, C. C.; FREITAS, E. C. D. Metodologia do Trabalho Científico: Métodos e Técnicas da Pesquisa e do Trabalho Acadêmico. 2. ed. Novo Hamburgo: Editora Feevale, 2013.

RAPINI, M. S. A natureza do financiamento influencia na interação universidadeempresa no Brasil? Revista Brasileira de Inovação, v. 13, n. 1, jan./jun. 2014.

ROGERS, E. Diffusion of innovations. 5. ed. New York: Free Press, 2003.

SAMPIERE, R. H.; COLLADO, C. F.; LUCIO, P. B. Metodologia de Pesquisa. 3. ed. São Paulo: McGraw-Hill, 2006. 
SANTOS, A. R. Metodologia científica: a construção do conhecimento. Rio de Janeiro: DP\&A, 1999.

SCHUMPETER, J. A. Teoria do desenvolvimento econômico: uma investigação sobre lucros, capital, crédito, juro e ciclo econômico. Tradução de Maria Sílvia Possas. São Paulo: Nova Cultural, 1997.

SEGATTO-MENDES, A. P. Análise do processo de cooperação tecnológica Universidade-Empresa: um estudo exploratório. 1996. 175 f. Dissertação (Mestrado em Administração) - Universidade de São Paulo, São Paulo, 1996.

SEGATTO-MENDES, A. P.; SBRAGIA, R. O processo de cooperação universidadeempresa em universidades brasileiras. Revista de Administração, São Paulo, v. 37, n. 4, p. 57-71, out./dez. 2002.

SOUZA, J. V. Expansão e Avaliação da educação superior brasileira: formatos, desafios e novas configurações. Belo Horizonte: Fino Traço/Faculdade de Educação da Universidade de Brasília, 2015.

TECCHIO, E. L. et al. Cooperação Universidade-Segmento Empresarial: dificuldades e mecanismos facilitadores do processo. In: COLÓQUIO INTERNACIONAL SOBRE GESTÍON UNIVERSITÁRIA EN AMERICA DEL SUR, 10., Mar del Plata, 2010. Anais... Mar del Plata, Argentina: Universidade Nacional de Mar Del Plata, 2010. TERRA, B. R. C.; PLONSKI, G. A. Metodologias para formação de redes de desenvolvimento: um estudo benchmarking da regional inovation system RIS, na União Europeia - EU e das plataformas tecnológicas - PLAT, no Brasil. In: SIMPÓSIO DE GESTÃO DA INOVAÇÃO TECNOLÓGICA, 24., Gramado, 2006. Anais... Gramado, RS: ANPAD, 2006.

TIROLE, J. The Theory of Industrial Organization. Massachusetts: MIT Press, 1995.

TORRES, J. C. B. Manual de ética: questões de ética teórica e aplicada. Petrópolis, RJ: Vozes, 2014.

TOSCANO, F. L. P.; RIBEIRO, A. C. A tríplice hélice e o desenvolvimento regional no Brasil. In: ENCONTRO NACIONAL DE ENGENHARIA DE PRODUÇÃO, 29., Salvador, 2009. Anais... Salvador: ABEPRO, 2009.

VASCONCELLOS, E.; WAACK, R.; VASCONCELLOS, L. Inovação e competitividade. In: ENCONTRO ANUAL DA ANPAD, 21., Angra dos Reis, 1997. Anais Eletrônicos... Rio de Janeiro: ANPAD, 1997. 
WEBSTER, A. International evaluation of academic-industry relations: contexts and analysis. Science and Public Policy, v. 21, n. 2, p. 72-80, 1994.

YIN, R. K. Estudo de caso: planejamento e métodos. 2. ed. Porto Alegre: Bookman, 2001. 